\title{
A novel quantitative method for estimating bone mineral density using B-mode ultrasound and radiofrequency signals-a pilot study on patients with rheumatoid arthritis
}

\author{
VIOLETA-CLAUDIA BOJINCĂ ${ }^{1 *}$, CLAUDIU C. POPESCU ${ }^{2 *}$, RALUCA-DANIELA DECIANU $^{1 *}$, \\ ANDREI DOBRESCU ${ }^{1 *}$, ȘERBAN MIHAI BĂLĂNESCU ${ }^{3 *}$, ANDRA-RODICA BĂLĂNESCU $^{1 *}$ and MIHAI BOJINCĂ $\breve{4}^{*}$ \\ ${ }^{1}$ Internal Medicine and Rheumatology Department, Sfânta Maria Clinical Hospital, Carol Davila University of Medicine and \\ Pharmacy, Bucharest 011172; ${ }^{2}$ Ion Stoia Clinical Centre for Rheumatic Diseases, Carol Davila University of Medicine and \\ Pharmacy, Bucharest 031167; ${ }^{3}$ Cardiology Department, Elias University Emergency Hospital, Carol Davila University of \\ Medicine and Pharmacy, Bucharest 011461; ${ }^{4}$ Rheumatology Department, Dr I. Cantacuzino Clinical Hospital, \\ Carol Davila University of Medicine and Pharmacy, Bucharest 030167, Romania
}

Received December 11, 2018; Accepted May 31, 2019

DOI: $10.3892 / \mathrm{etm} .2019 .7746$

\begin{abstract}
The objective of the present study was to evaluate whether an innovative quantitative ultrasound (QUS) technique, Radiofrequency Echographic Multi Spectromety, which combines B-mode ultrasound and radiofrequency signals, is reliable in typical Romanian patients compared to previous results obtained using dual-energy X-ray absorptiometry (DXA). The study prospectively included previously unscreened post-menopausal females with rheumatoid arthritis (RA) and age-matched healthy controls. Bone mineral density (BMD) measurements were performed with an EchoS machine $\left(\right.$ Echolight $\left.^{\circledR}\right)$, which combines B-mode ultrasound and radiofrequency signals. The study included 106 RA patients, with a median disease duration of 3.2 (0.5-22) years and 119 controls. RA patients had a significantly lower body weight, body mass index (BMI) and basal metabolic rate (BMR) than the controls, while the prevalence of obesity and body fat differed insignificantly. RA patients had a significantly lower spine and hip BMD, higher fracture risk and higher prevalence of osteoporosis. Compared to RA patients without osteoporosis, those with osteoporosis were significantly older and had a longer menopause duration, but they had a significantly lower BMI, body fat, BMR and prevalence of obesity. Among the controls and RA patients, the
\end{abstract}

Correspondence to: Dr Violeta-Claudia Bojincă, Internal Medicine and Rheumatology Department, Sfânta Maria Clinical Hospital, Carol Davila University of Medicine and Pharmacy, 37-39 Ion Mihalache Boulevard, Bucharest 011172, Romania E-mail: vmbojinca@yahoo.com

*Contributed equally

Key words: quantitative ultrasound, rheumatoid arthritis, osteoporosis median spine and hip BMD became significantly higher as the BMI increased from underweight to obesity. In conclusion, osteoporosis is prevalent among RA patients, as a part of a complex transformation of body mass composition, involving BMI and fat mass. The novel QUS scanning technique was able to replicate the results of the established DXA measurement of BMD and is potentially suitable for screening wide populations for osteoporosis.

\section{Introduction}

In an aging European population, osteoporosis has become a major public health problem. It increases morbidity and mortality (1-3) and it leads to high direct and indirect medical costs $(4,5)$ for society due to its hallmark clinical manifestation: Fragility fractures, particularly vertebral and hip fractures. The population at risk includes post-menopausal females, the elderly, patients with long-term glucocorticoid treatment and patients with chronic inflammatory diseases, e.g. rheumatoid arthritis (RA). Patients with this auto-immune inflammatory disease constitute a special subpopulation of patients prone to osteoporosis, since they possess multiple risk factors for systemic bone loss: Chronic inflammation of uncontrolled disease activity (6), higher prevalence of early menopause (7), increased smoking and alcohol consumption due to RA-associated stress and depression (8-10), physical disability and sedentary behavior caused by $\mathrm{RA}$ radiographic progression $(11,12)$ and treatment with glucocorticoids $(13)$, which are independently involved in lowering bone mineral density (BMD). Complex management principles of RA should include strategies to reduce these risk factors and should promote osteoporosis screening among RA patients. Unfortunately, a large fraction of patients is still being diagnosed with osteoporosis at the late stage, after a fragility fracture. Thus, early detection of osteoporosis and prevention of its complications are important and require a reliable and reproducible method, accessible to rheumatologists in all clinical settings. Dual-energy X-ray absorptiometry (DXA) 
is the current validated 'gold standard' for the diagnosis of osteoporosis, fracture risk estimation and follow-up of anti-osteoporotic treatment (14-16), since it is non-invasive, simple, precise, fast, less expensive than other imaging techniques, including computed tomography and magnetic resonance imaging, and more sensitive than quantitative ultrasound (QUS) (17). DXA and QUS offer the advantage of body composition estimation. However, QUS may have particular advantages over DXA, which make it suitable for a potentially wider use in the primary screening or pre-screening of osteoporosis and the identification of cases requiring DXA scanning $(18,19)$ : It is less expensive, does not use ionising radiation, uses smaller hardware and is portable. A recently introduced QUS method that integrates ultrasound imaging and radiofrequency signals is being used for the diagnosis of osteoporosis and it produced results comparable to those obtained with the DXA method $(20,21)$. To the best of our knowledge, this technique has never been used in a controlled study environment to assess BMD in Romanian RA patients and healthy controls. Therefore, the objective of the present study was to observe whether this innovative QUS technique is reliable compared to DXA in a typical sample of Romanian patients. In the first stage of the present study, Romanian RA patients and healthy controls were pre-screened for osteoporosis using a novel QUS machine, in order to compare the two groups in terms of bone parameters and to observe the influence of body composition on BMD and osteoporosis outcomes.

\section{Patients and methods}

Patients and variables. The present study prospectively included post-menopausal females diagnosed with RA, who also fulfilled the latest classification criteria (22). Age-matched controls were recruited from healthy post-menopausal females presenting at the rheumatology department in the same time period due to osteoarthritis or occupational musculoskeletal complaints. All of the subjects were examined between January and June 2018 in a random order of arrival at two rheumatology clinics of university hospitals with national addressability (Rheumatology Department of Sfânta Maria Clinical Hospital and 'Dr I. Cantacuzino' Clinical Hospital). Neither the RA patients nor the controls had been subjected to a DXA scan or had a known diagnosis of osteoporosis prior to inclusion in the study; therefore, none of them were receiving any active pharmacologic treatment (bisphosphonates, hormone replacement therapy, teriparatide, denosumab, strontium ranelate or vitamin D supplements). Prior to any study procedure, each patient provided written informed consent and the study was approved by the Ethics Committee of Sfanta Maria Clinical Hospital (no. 21440; 22.12.2017). The patients were evaluated for the following exclusion criteria that were applied: Age <18 years; overlap syndromes of RA with other chronic auto-immune inflammatory rheumatologic disorders or their presence in the control group; causes of secondary osteoporosis, either in the patient's history or diagnosed during the study by each attending physician (cancer, celiac disease, chronic liver disease, chronic pancreatitis, chronic renal disease, chronic obstructive pulmonary disease, Cushing's disease, cystic fibrosis, diabetes mellitus, hemoglobinopathies, heparin treatment, hypogonadism, hyperthyroidism, inflammatory bowel disease, immobility, malabsorption). Body height and weight were measured in an upright anatomical position, with light clothing and no shoes, using a mechanical scale $(0.1 \mathrm{~kg}$ maximal error) and a stadiometer $(0.3 \mathrm{~cm}$ maximal error). The body mass index (BMI) was calculated by dividing the body weight by the square of the height and the following weight categories were defined (23): Underweight $\left(\mathrm{BMI}<18.5 \mathrm{~kg} / \mathrm{m}^{2}\right)$, normal weight $\left(18.5 \leq \mathrm{BMI}<25 \mathrm{~kg} / \mathrm{m}^{2}\right)$, overweight $\left(25 \leq \mathrm{BMI}<30 \mathrm{~kg} / \mathrm{m}^{2}\right)$ and obese $\left(\mathrm{BMI} \geq 30 \mathrm{~kg} / \mathrm{m}^{2}\right)$.

BMD measurement. All of the measurements were performed by a single trained technologist using an EchoS machine (Echolight ${ }^{\circledR}$; Echolight SRL), which uses quantitative ultrasonometry to estimate bone density and structure. The system is equipped with a convex $3.5 \mathrm{MHz}$ transducer, which simultaneously detects B-mode ultrasound signals and unprocessed radiofrequency signals. Those which are analyzed by the machine's statistical algorithm (EchoStudio ${ }^{\circledR}$; Echolight SRL) for each region of interest (ROI), taking into account the patient's ethnicity, age, sex and BMI and comparing them to a database of $\sim 10,000$ subjects $(18,20,24-26)$. The ROI for each patient included the usual sites for the diagnosis of osteoporosis: The lumbar spine (L1-L4 vertebrae approached from the abdomen) and the femoral necks. The machine's software outputs the following measurements: 10-year risk of major osteoporotic and hip fractures (Fracture Risk Assessment Tool; FRAX ${ }^{\circledR}$ ), calculated according to the established algorithm (27), BMD $\left(\mathrm{g} / \mathrm{cm}^{2}\right)$ with $\mathrm{T}$ and $\mathrm{Z}$ scores [standard deviations (SD)], body fat percentage and basal metabolic rate [BMR (kcal/day)]. The producer reported the following quality and precision $(15,28)$ parameters for the machine: Minimal detectable change of $0.013 \mathrm{~g} / \mathrm{cm}^{2}$ for the spine and $0.008 \mathrm{~g} / \mathrm{cm}^{2}$ for the hip; intra-operator reproducibility of $0.4 \%$ for the spine and $0.3 \%$ for the hip; inter-operator reproducibility of $0.54 \%$ for the spine and $0.41 \%$ for the hip; diagnostic correlation with DXA of $93.1 \%$ for the spine and $94.2 \%$ for the hip. In the present study, osteoporosis was defined by a T score for the spine or either hip of $\leq-2.5 \mathrm{SD}$.

Statistics. Normality of distribution of data was assessed using descriptive statistics, normality plots and Lillefors corrected Kolmogorov-Smirnov tests. Normally distributed continuous variables are expressed as the mean \pm standard deviation, while non-normally distributed variables are expressed as the median (minimum-maximum). Qualitative variables are expressed as absolute frequency (fraction of subgroup). The correlations of normally distributed continuous variables were assessed using 2-tailed partial correlations controlling for recorded confounders. The difference of continuous variables between subgroups (RA and controls or RA patients with or without osteoporosis) was assessed by independent-samples t-tests or Mann-Whitney U-tests, depending on their normality of distribution, while differences of nominal variables were assessed with $\chi^{2}$ tests. The distribution of BMD measurements among RA patients according to weight category was assessed using independent-samples Kruskal-Wallis tests. $\mathrm{P}<0.05$ was considered to indicate statistical significance. Statistical analysis was performed using SPSS v.20 for Windows (IBM Corp.). 
Table I. Comparison of clinicopathological characteristics between subjects with RA and controls.

\begin{tabular}{|c|c|c|c|}
\hline Parameter & Controls $(\mathrm{n}=119)$ & $\mathrm{RA}(\mathrm{n}=106)$ & P-value \\
\hline Age (years) & $64 \pm 13$ & $65 \pm 8$ & $0.448^{\mathrm{a}}$ \\
\hline Menopause (years) & $10(1-42)$ & $17(1-45)$ & $0.223^{\mathrm{b}}$ \\
\hline Height (m) & $1.6 \pm 0.1$ & $1.6 \pm 0.1$ & $0.166^{\mathrm{a}}$ \\
\hline Weight (kg) & $68(42-109)$ & $65(45-95)$ & $0.011^{\mathrm{b}}$ \\
\hline BMI $\left(\mathrm{kg} / \mathrm{m}^{2}\right)$ & $27(18-41)$ & $26(18-38)$ & $0.039^{\mathrm{b}}$ \\
\hline Obesity (\%) & $34(28.6 \%)$ & $25(23.6 \%)$ & $0.396^{\mathrm{c}}$ \\
\hline Body fat (\%) & $35.4 \pm 5.5$ & $35.5 \pm 6.6$ & $0.257^{\mathrm{a}}$ \\
\hline $\operatorname{BMR}(1,000 \mathrm{kcal} /$ day $)$ & $1.3(0.9-2.8)$ & $1.2(0.8-2.6)$ & $0.038^{\mathrm{b}}$ \\
\hline Spine T-score (SD) & $-1.8(-3.2-1.5)$ & $-1.9(-4.2-1.2)$ & $0.110^{\mathrm{b}}$ \\
\hline Spine BMD $\left(\mathrm{g} / \mathrm{cm}^{2}\right)$ & $0.89 \pm 0.13$ & $0.87 \pm 0.09$ & $0.035^{\mathrm{a}}$ \\
\hline Spine FRAX-mof $(\%)$ & $4.1(1.2-6.2)$ & $6.3(1.9-15.2)$ & $<0.001^{\mathrm{b}}$ \\
\hline Spine FRAX-hf (\%) & $0.8(0-8.2)$ & $2.1(0.8-12.5)$ & $<0.001^{\mathrm{b}}$ \\
\hline Left femoral neck T-score (SD) & $-1.7(-2.8-1.2)$ & $-2.0(-3.9-0.8)$ & $0.039^{\mathrm{b}}$ \\
\hline Left femoral neck BMD $\left(\mathrm{g} / \mathrm{cm}^{2}\right)$ & $0.71 \pm 0.13$ & $0.67 \pm 0.12$ & $0.021^{\mathrm{a}}$ \\
\hline Left hip FRAX-mof $(\%)$ & $4.9(0-8.1)$ & $6.6(1-13.2)$ & $<0.001^{\mathrm{b}}$ \\
\hline Left hip FRAX-hf (\%) & $1.2(0-5.2)$ & $1.8(0.9-11.6)$ & $<0.001^{\mathrm{b}}$ \\
\hline Right femoral neck T-score (SD) & $-1.7(-2.7-1.5)$ & $-2.0(-3.7-1.2)$ & $0.030^{\mathrm{b}}$ \\
\hline Right femoral neck BMD $\left(\mathrm{g} / \mathrm{cm}^{2}\right)$ & $0.71 \pm 0.12$ & $0.67 \pm 0.12$ & $0.041^{\mathrm{a}}$ \\
\hline Right hip FRAX-mof (\%) & $4.6(0-5.1)$ & $6.4(1-12.8)$ & $<0.001^{\mathrm{b}}$ \\
\hline Right hip FRAX-hf (\%) & $1.0(0-4.8)$ & $1.7(1.1-10.2)$ & $<0.001^{\mathrm{b}}$ \\
\hline Osteoporosis (\%) & $16(13.4 \%)$ & $30(28.3 \%)$ & $0.006^{\mathrm{c}}$ \\
\hline
\end{tabular}

Values expressed as ${ }^{\text {at }}$ the mean (standard deviation) if normally distributed with significant differences between groups assessed with independent-samples t-tests, bthe median (minimum-maximum) if non-normally distributed and statistical significance was assessed with Mann-Whitney U-tests or cabsolute frequency (percent proportion from subgroup) if nominal and $\chi^{2}$ tests were used to assess significant differences between groups. BMD, bone mineral density; BMI, body mass index; BMR, basal metabolic rate; FRAX, Fracture Risk Assessment Tool; hf, hip fracture; mof, major osteoporotic fracture; RA, rheumatoid arthritis; SD, standard deviation.
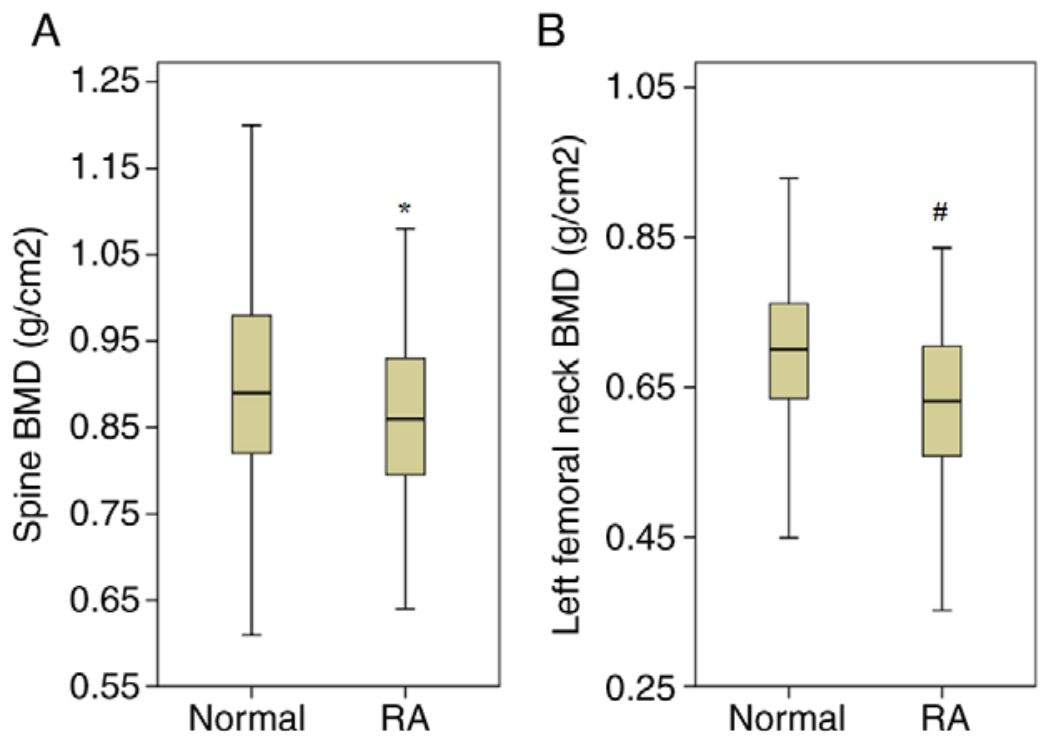

Figure 1. Differences in BMD between RA patients and controls, measured at (A) the lumbar spine (median, $0.87 \mathrm{vs} .0 .87 \mathrm{~g} / \mathrm{cm}^{2} ;{ }^{*} \mathrm{P}=0.035, \mathrm{t}$-test) and (B) the left femoral neck (median, 0.67 vs. $0.71 \mathrm{~g} / \mathrm{cm}^{2} ;{ }^{\#} \mathrm{P}=0.021$, t-test). RA, rheumatoid arthritis; BMD, bone mineral density.

\section{Results}

General characteristics. The study included 225 subjects:
106 RA patients $(47.1 \%)$, with an average age of $65 \pm 8$ years and 119 controls $(52.9 \%)$ with an average age of $64 \pm 13$ years (Table I). The median disease duration of RA was 3.2 
Table II. Comparison of clinicopathological parameters between RA patients with and without osteoporosis.

\begin{tabular}{|c|c|c|c|}
\hline \multirow[b]{2}{*}{ Parameter } & \multicolumn{2}{|c|}{ Osteoporosis } & \multirow[b]{2}{*}{ P-value } \\
\hline & No $(n=76)$ & Yes $(n=30)$ & \\
\hline Age (years) & $60(42-82)$ & $69(36-84)$ & $<0.001^{\mathrm{a}}$ \\
\hline Menopause (years) & $13(1-38)$ & $26(1-42)$ & $<0.001^{\mathrm{a}}$ \\
\hline Height (cm) & $161(151-185)$ & $160(152-182)$ & $<0.001^{\mathrm{a}}$ \\
\hline Weight (kg) & $70(46-95)$ & $55(42-82)$ & $<0.001^{\mathrm{a}}$ \\
\hline $\mathrm{BMI}\left(\mathrm{kg} / \mathrm{m}^{2}\right)$ & $27(18-36)$ & $22(18-31)$ & $<0.001^{\mathrm{a}}$ \\
\hline Obesity (\%) & $23(21.7 \%)$ & $2(1.9 \%)$ & $0.010^{\mathrm{b}}$ \\
\hline Body fat (\%) & $37(30-61)$ & $28(28-52)$ & $0.001^{\mathrm{a}}$ \\
\hline $\operatorname{BMR}(1,000 \mathrm{kcal} /$ day $)$ & $1.3(0.8-2.8)$ & $1.1(0.8-2.5)$ & $<0.001^{\mathrm{a}}$ \\
\hline
\end{tabular}

Osteoporosis was defined by a spine or either hip T score of $\leq-2.5 \mathrm{SD}$. Values expressed as ${ }^{\text {at }}$ the median (minimum-maximum) if non-normally distributed and statistical significance was assessed with Mann-Whitney U-tests or ${ }^{b}$ absolute frequency (percent proportion from subgroup) if nominal and $\chi^{2}$ tests were used to assess significant differences between groups. BMI, body mass index; BMR, basal metabolic rate; RA, rheumatoid arthritis; SD, standard deviation.

(1.5-42.0) years and all RA patients were receiving at least one conventional synthetic disease-modifying anti-rheumatic drug: Methotrexate (77.4\%), leflunomide (18.9\%), sulfasalazine $(12.3 \%)$ and/or hydroxychloroquine $(8.5 \%)$. All of the RA patients had received glucocorticoids for different periods of time during the disease course, but 14 patients (13.2\%) were still taking glucocorticoids at the time of study inclusion. The mean dose of glucocorticoids in the 3 months prior to study inclusion was 8.9 (4.0-15.0) $\mathrm{mg}$ of prednisone/day or equivalent.

Inter-group comparison. Comparing the two groups, significant differences became apparent: The RA patients had a significantly lower body weight and BMI and BMR than the controls, although the prevalence of obesity and body fat percentage differed insignificantly (Table I). Regarding bone measurements, RA patients had a significantly lower spine and hip BMD (Fig. 1), higher fracture risks according to FRAX scores and higher prevalence of $\mathrm{T}$ score-defined osteoporosis (Table I).

RA subgroup analysis. RA patients were also studied independently regarding their osteoporosis status: Patients with or without osteoporosis were compared (Table II). Compared to non-osteoporotic RA patients, RA patients with osteoporosis were significantly older and had a longer menopause duration, but they had a significantly lower percentage of body fat ( $28 \%$ compared to $37 \%$ respectively; $\mathrm{P}<0.001$; Fig. 2), BMI, prevalence of obesity and BMR (Table II). Median BMD values increased proportionally and significantly with weight category (Fig. 3). Body fat and BMD at all three scanning sites were significantly and positively correlated when controlling for age, menopause duration and BMI (Table III).

\section{Discussion}

Regarding the aims of the present study, implementation of the novel QUS technique revealed a higher prevalence of

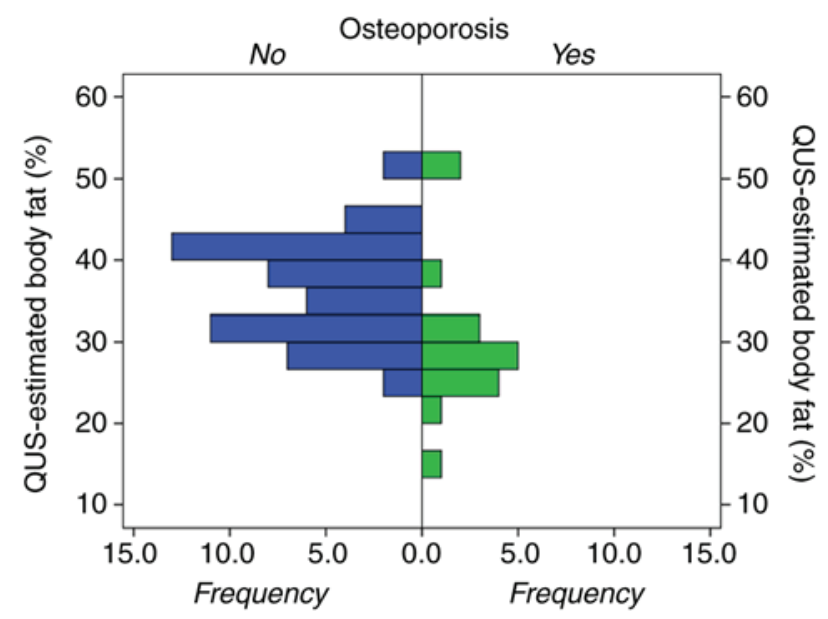

Figure 2. Differences in body fat between rheumatoid arthritis patients with osteoporosis (median 28.1\%) and without osteoporosis determined with QUS (median, 36.7\%; P<0.001; Mann-Whitney U-test). QUS, quantitative ultrasound.

osteoporosis among RA patients compared to controls, which in turn caused higher fragility fracture risks according to FRAX, which is well documented in the literature in studies using DXA (29-31). The fraction of RA patients with osteoporosis was previously reported to be up to $50 \%$ (30), but the $28.3 \%$ prevalence of osteoporosis among the RA patients in the present study is similar to that determined by other European DXA-defined studies on the prevalence of osteoporosis: For instance, Hauser et al (29) reported that $29.9 \%$ of their RA patients had osteoporosis, while Mobini et al (31) reported a slightly higher prevalence of $32.3 \%$. RA is highly associated with osteoporosis: The rate of BMD decline in females with RA is significantly higher than that of controls in all age groups (29) and $10 \%$ of females with RA with a normal initial BMD develop osteoporosis within a decade (32). Positive rheumatoid factor and anti-citrullinated protein antibodies (31), RA disease duration (30), quality of life (30) and glucocorticoids (33) are specific 


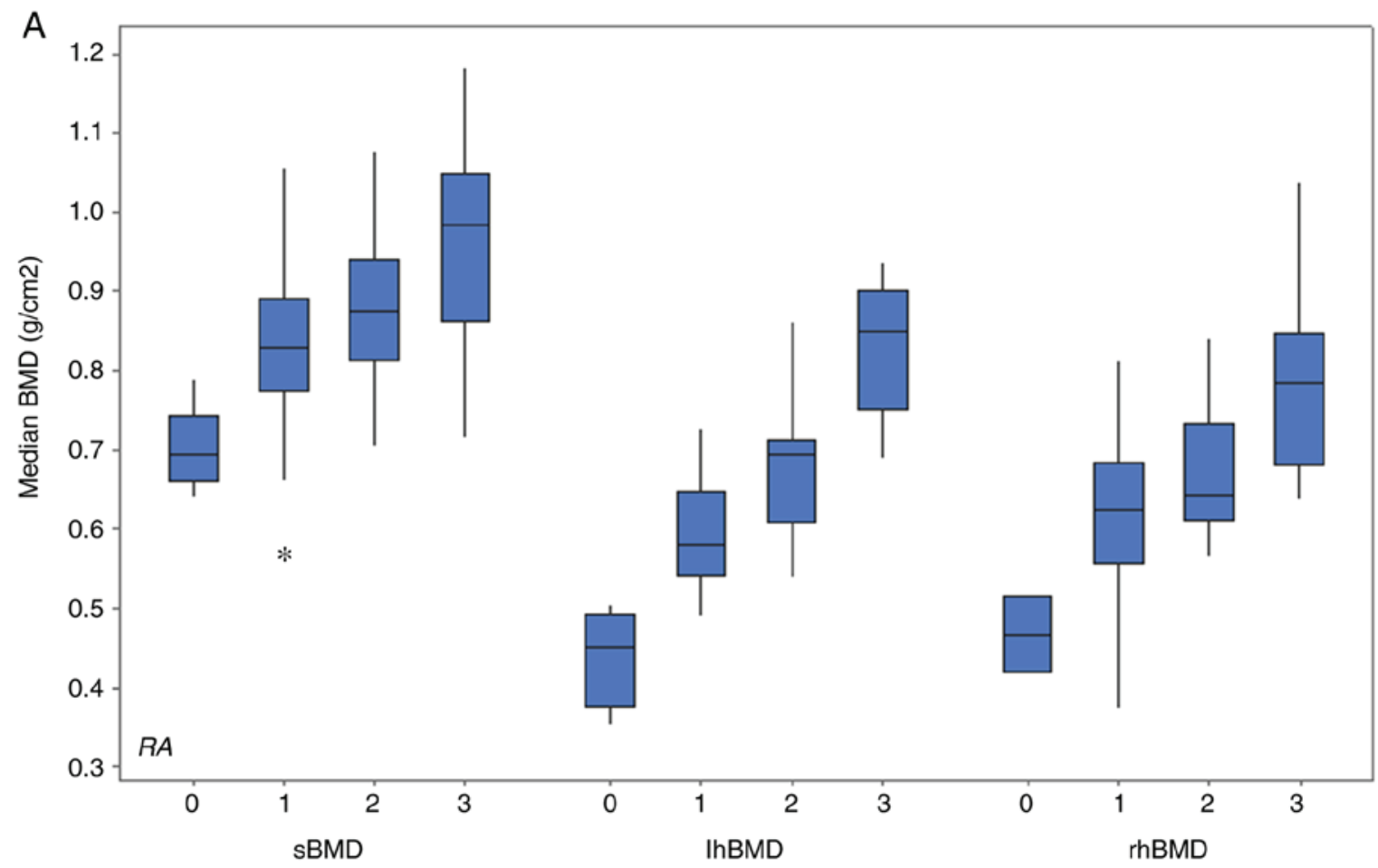

B

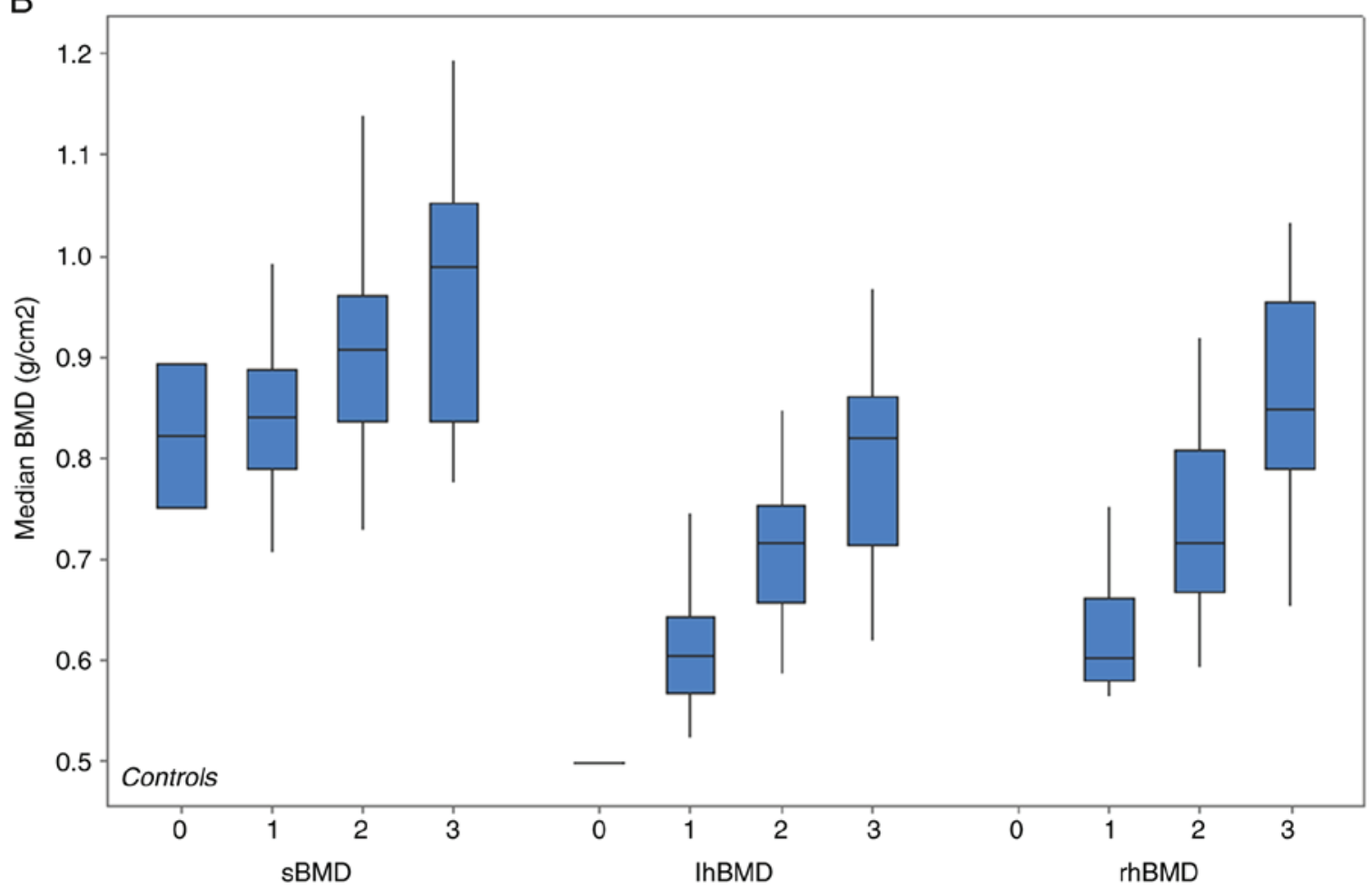

Figure 3. Distribution of median BMD among RA patients and controls at the spine, left and right femoral neck according to weight category. (A) For RA patients: Underweight $\left(\mathrm{n}=5 ; \mathrm{sBMD}=0.69 \mathrm{~g} / \mathrm{cm}^{2} ; 1 \mathrm{fnBMD}=0.45 \mathrm{~g} / \mathrm{cm}^{2} ; \mathrm{rfnBMD}=0.47 \mathrm{~g} / \mathrm{cm}^{2}\right)$, normal weight $\left(\mathrm{n}=43 ; \mathrm{sBMD}=0.83 \mathrm{~g} / \mathrm{cm}^{2} ; 1 \mathrm{fnBMD}=0.58 \mathrm{~g} / \mathrm{cm}^{2}\right.$; $\left.\mathrm{rfnBMD}=0.62 \mathrm{~g} / \mathrm{cm}^{2}\right)$, overweight $\left(\mathrm{n}=33 ; \mathrm{sBMD}=0.87 \mathrm{~g} / \mathrm{cm}^{2} ; 1 \mathrm{fnBMD}=0.69 \mathrm{~g} / \mathrm{cm}^{2} ; \mathrm{rfnBMD}=0.64 \mathrm{~g} / \mathrm{cm}^{2}\right)$ and obese $\left(\mathrm{n}=25 ; \mathrm{sBMD}=0.98 \mathrm{~g} / \mathrm{cm}^{2} ; 1 \mathrm{fnBMD}=0.85 \mathrm{~g} / \mathrm{cm}^{2} ;\right.$ $\left.\mathrm{rfnBMD}=0.78 \mathrm{~g} / \mathrm{cm}^{2}\right)$. (B) For controls: Underweight $(\mathrm{n}=2)$, normal weight $\left(\mathrm{n}=34 ; \mathrm{sBMD}=0.84 \mathrm{~g} / \mathrm{cm}^{2} ; 1 \mathrm{fnBMD}=0.61 \mathrm{~g} / \mathrm{cm}^{2} ; \mathrm{rfnBMD}=0.61 \mathrm{~g} / \mathrm{cm}^{2}\right)$, overweight $\left(\mathrm{n}=49 ; \mathrm{sBMD}=0.91 \mathrm{~g} / \mathrm{cm}^{2} ; 1 \mathrm{fnBMD}=0.72 \mathrm{~g} / \mathrm{cm}^{2} ; \mathrm{rfnBMD}=0.72 \mathrm{~g} / \mathrm{cm}^{2}\right)$ and obese $\left(\mathrm{n}=34 ; \mathrm{sBMD}=0.99 \mathrm{~g} / \mathrm{cm}^{2} ; 1 \mathrm{fnBMD}=0.82 \mathrm{~g} / \mathrm{cm}^{2} ; \mathrm{rfnBMD}=0.85 \mathrm{~g} / \mathrm{cm}^{2}\right)$. All comparisons were tested with Kruskal-Wallis tests ( $\mathrm{P}<0.001$ for all). RA, rheumatoid arthritis; sBMD, spine bone mineral density; $1 / \mathrm{rfn}$, left/right femoral neck.

risk factors for osteoporosis in RA, proving that the association of the two diseases is causal. This assumption is further documented by genetic studies, which revealed $>30$ genetic factors of the RA-osteoporosis association (34), including the 14-3-3e protein $(35)$ and polymorphisms of vitamin D receptors $(36,37)$ and of receptor activator of NF- $\mathrm{kB}$ (38). This strong link is the fundamental reason for the requirement of intensive and extensive osteoporosis screening and treatment of RA patients, a goal which may be achieved by exploiting the physical advantages of QUS methods. 
Table III. Correlation of body fat with BMD controlling for age, menopause duration and body mass index.

\begin{tabular}{|c|c|c|c|c|c|c|}
\hline & \multicolumn{2}{|c|}{ All (n=225) } & \multicolumn{2}{|c|}{ RA group (n=106) } & \multicolumn{2}{|c|}{ Control group $(\mathrm{n}=119)$} \\
\hline & $\mathrm{r}$ & P-value & $\mathrm{r}$ & P-value & $\mathrm{r}$ & P-value \\
\hline Spine BMD & 0.663 & $<0.001$ & 0.645 & $<0.001$ & 0.674 & $<0.001$ \\
\hline Left hip BMD & 0.622 & $<0.001$ & 0.691 & $<0.001$ & 0.572 & $<0.001$ \\
\hline Right hip BMD & 0.697 & $<0.001$ & 0.514 & 0.003 & 0.777 & $<0.001$ \\
\hline
\end{tabular}

BMD, bone mineral density; RA, rheumatoid arthritis.

In terms of body composition, an insignificant difference in body fat was observed among RA patients and controls, as estimated by the novel QUS method, a result which replicates a similar previous observation of our group using DXA (39). Considering the fact that the RA patients of the present study had a significantly lower median body weight and BMD in the selected ROI compared with those of the controls, it may be hypothesized that the RA patients had a lower muscle mass than the controls, which is in accordance with literature reports of higher prevalence of cachexia and sarcopenia among RA patients (40-42), and/or that there was a selection bias of controls (the fact that these subjects solicited medical attention may translate to a higher morbidity toll than the remainder of the healthy Romanian population, including obese individuals). Of note, in the present study, the RA patients with osteoporosis had a significantly lower median BMI and QUS-estimated body fat than the RA patients without osteoporosis. If this lower BMI is explained by a lower body fat mass, this observation is explainable by the trend reported in the general population of a low BMI being associated with an increased risk of osteoporosis $(43,44)$, which translates into the lack of the protective effect of adiposity against systemic bone loss. If the observed lower BMI of RA patients with osteoporosis was not due to their lower body fat mass, it must be assumed that these patients had a loss of therapeutic control of their disease activity which is expected to decrease BMI through cytokine production. In the association of BMI and BMD, the significant inflexion point of increasing BMD appears to be between BMI-defined overweight and obese RA patients and between BMI-defined normal-weight and overweight controls, which graphically demonstrates that overweight RA patients experience the same BMD effect as normal-weight controls, reaffirming the requirement to lower BMI cutoffs in RA patients, since there is DXA evidence that the traditional $30 \mathrm{~kg} / \mathrm{m}^{2}$ cutoff for obesity is too high for RA patients (45). It may also suggest that there is a critical adipose tissue mass [or its biochemical products, including estrogens, androgens and leptin (46)], which is required counteract systemic bone loss. Clinicians should be aware of body composition trends in their RA patients, as evidence suggests that patients with early RA tend to lose their lean body mass status and gain truncal fat distribution (47), and that these modifications in body composition may be significantly predicted by RA-specific variables, including disease duration, disease activity scores and radiographic progression (48). Complex management of RA (control of disease activity and cardiovascular risk factors) should aim to prevent or reverse these changes in body composition, with additional long-term effects or lowering of mortality by decreasing cardiovascular and fracture complications.

There are several limitations of the present study, which may influence the relevance of the results, including its cross-sectional design (which, at this time, did not allow for follow-up QUS scans in order to assess the evolution in time and the effect of therapeutic intervention), hospital-recruited study samples (which may have been biased regarding the presence of comorbidities) and the lack of data regarding disease activity (including composite disease activity scores, which would have allowed for evaluation of the association of QUS measurements and the inflammation burden). Future research efforts will aim to bring improvements to the design of the present preliminary study on the novel QUS technique in detecting osteoporosis in post-menopausal females with or without RA, including direct comparison with DXA results, inclusion of more study groups with other rheumatic diseases and, in a longer term, to evaluate the cost-effectiveness of this portable QUS method in a wider screening program.

This innovative, non-ionizing technique Radiofrequency Echographic Multi Spectrometry (REMS) used for diagnosing osteoporosis was recently evaluated through a multicenter study that involved 1914 women and the results obtained with this method were significantly in agreement with those obtained using the gold standard lumbar spine and femoral neck DXA evaluation. Regarding its diagnostic capability, REMS evaluation had a sensitivity and specificity of $>90 \%$ for the two anatomic sites that were measured (48). It should be mentioned that on 21 September 2018, at the meeting of the International Scientific Advisory Board of Echolight in Florence, Prof. Dr. Jean-Yves Reginster, president of the European Society for Clinical and Economic Aspects of Osteoporosis, Osteoarthritis and Musculoskeletal Diseases (ESCEO), signed a letter in the name of the organization, recommending the inclusion of REMS technology into clinical practice guidelines for the diagnosis and treatment of osteoporosis. The letter mentioned the fact that ESCEO is considering to publish a position paper discussing the potentialities of REMS technology for the early diagnosis of osteoporosis and for monitoring treatment effects. This method will be considered at the next revision of the ESCEO clinical practice guidelines.

In conclusion, osteoporosis is prevalent among RA patients, increasing their fragility fracture risk, and is part of a more complex pathological process of alteration of body mass 
composition, involving BMI and fat mass. The novel scanning technique, which combines B-mode ultrasound and radiofrequency signals, is able to replicate the results of the established DXA measurements of BMD and is potentially suitable for the screening of wide populations for osteoporosis.

\section{Acknowledgements}

Not applicable.

\section{Funding}

No funding was received.

\section{Availability of data and materials}

The datasets generated and/or analyzed during the current study are available from the corresponding author on reasonable request.

\section{Authors' contributions}

VCB was responsible for the study design, ultrasonographic densitometric determinations and writing of the manuscript. CCP was responsible for the statistical analysis and writing of the manuscript. RDD and AD were responsible for the recruitment of patients and performed the ultrasonographic densitometric determinations. SMB and ARB made substantial contributions to the conception or design of the work. MB was responsible for the recruitment of patients, provided scientific advice and critically reviewed the manuscript. All authors read and approved the final manuscript.

\section{Ethics approval and consent to participate}

Each patient provided written informed consent and the study was approved by the Ethics Committee of Sfanta Maria Clinical Hospital (no. 21440; 22.12.2017).

\section{Patient consent for publication}

Not applicable.

\section{Competing interests}

The authors declare that they have no competing interests.

\section{References}

1. Bliuc D, Alarkawi D, Nguyen TV, Eisman JA and Center JR: Risk of subsequent fractures and mortality in elderly women and men with fragility fractures with and without osteoporotic bone density: The Dubbo Osteoporosis Epidemiology Study. J Bone Miner Res 30: 637-646, 2015.

2. Diamantopoulos AP, Hoff M, Skoie IM, Hochberg M and Haugeberg G: Short- and long-term mortality in males and females with fragility hip fracture in Norway. A population-based study. Clin Interv Aging 8: 817-823, 2013.

3. Gutzwiller JP, Richterich JP, Stanga Z, Nydegger UE, Risch L and Risch M: Osteoporosis, diabetes, and hypertension are major risk factors for mortality in older adults: An intermediate report on a prospective survey of 1467 community-dwelling elderly healthy pensioners in Switzerland. BMC Geriatr 18: 115, 2018.
4. Fujiwara S, Zhao X, Teoh C, Jaffe DH and Taguchi Y: Disease burden of fractures among patients with osteoporosis in Japan: Health-related quality of life, work productivity and activity impairment, healthcare resource utilization, and economic costs. J Bone Miner Metab 37: 307-318, 2019.

5. Weycker D, Li X, Barron R, Bornheimer R and Chandler D: Hospitalizations for osteoporosis-related fractures: Economic costs and clinical outcomes. Bone Rep 5: 186-191, 2016.

6. Roux C: Osteoporosis in inflammatory joint diseases. Osteoporos Int 22: 421-433, 2011.

7. Banas T, Hajdyla-Banas I, Pitynski K, Nieweglowska D, Juszczyk G, Ludwin A, Knafel A and Ludwin I: Age at natural menopause in women on long-term methotrexate therapy for rheumatoid arthritis. Menopause 23: 1130-1138, 2016.

8. Chang K, Yang SM, Kim SH, Han KH, Park SJ and Shin JI: Smoking and rheumatoid arthritis. Int J Mol Sci 15: 22279-22295, 2014.

9. Matcham F, Rayner L, Steer S and Hotopf M: The prevalence of depression in rheumatoid arthritis: A systematic review and meta-analysis. Rheumatology (Oxford) 52: 2136-2148, 2013.

10. Matcham F, Rayner L, Steer S and Hotopf M: The prevalence of depression in rheumatoid arthritis: A systematic review and meta-analysis: Reply. Rheumatology (Oxford) 53: 578-579, 2014.

11. Bombardier C, Barbieri M, Parthan A, Zack DJ, Walker V, Macarios D and Smolen JS: The relationship between joint damage and functional disability in rheumatoid arthritis: A systematic review. Ann Rheum Dis 71: 836-844, 2012.

12. Legge A, Blanchard C and Hanly JG: Physical activity and sedentary behavior in patients with systemic lupus erythematosus and rheumatoid arthritis. Open Access Rheumatol 9: 191-200, 2017.

13. Kan SL, Yuan ZF, Li Y, Ai J, Xu H, Sun JC and Feng SQ: Alendronate prevents glucocorticoid-induced osteoporosis in patients with rheumatic diseases: A meta-analysis. Medicine (Baltimore) 95: e3990, 2016.

14. DeVita MV and Stall SH: Dual-energy X-ray absorptiometry: A review. J Ren Nutr 9: 178-181, 1999.

15. El Maghraoui A and Roux C: DXA scanning in clinical practice. QJM 101: 605-617, 2008

16. Tanner SB and Moore CF Jr: A review of the use of dual-energy $\mathrm{X}$-ray absorptiometry (DXA) in rheumatology. Open Access Rheumatol 4: 99-107, 2012.

17. El Maghraoui A, Morjane F, Mounach A, Ghazi M, Nouijai A, Achemlal L, Bezza A and Ghozlani I: Performance of calcaneus quantitative ultrasound and dual-energy X-ray absorptiometry in the discrimination of prevalent asymptomatic osteoporotic fractures in postmenopausal women. Rheumatol Int 29: 551-556, 2009.

18. Iida T, Chikamura C, Aoi S, Ikeda H, Matsuda Y, Oguri Y, Ono Y, Katada $\mathrm{K}$ and Ishizaki F: A study on the validity of quantitative ultrasonic measurement used the bone mineral density values on dual-energy X-ray absorptiometry in young and in middle-aged or older women. Radiol Phys Technol 3: 113-119, 2010.

19. Pisani P, Renna MD, Conversano F, Casciaro E, Muratore M, Quarta E, Paola MD and Casciaro S: Screening and early diagnosis of osteoporosis through X-ray and ultrasound based techniques. World J Radiol 5: 398-410, 2013.

20. Aventaggiato M, Conversano F, Pisani P, Casciaro E, Franchini R, Lay-Ekuakille A, Muratore M and Casciaro S: Validation of an automatic segmentation method to detect vertebral interfaces in ultrasound images. IET Sci Measurement Technol 10: 18-27, 2016.

21. Casciaro S, Peccarisi M, Pisani P, Franchini R, Greco A, De Marco T, Grimaldi A, Quarta L, Quarta E, Muratore M and Conversano F: An advanced quantitative echosound methodology for femoral neck densitometry. Ultrasound Med Biol 42: 1337-1356, 2016.

22. Aletaha D, Neogi T, Silman AJ, Funovits J, Felson DT, Bingham CO III, Birnbaum NS, Burmester GR, Bykerk VP, Cohen MD, et al: 2010 rheumatoid arthritis classification criteria: An American College of Rheumatology/European League Against Rheumatism collaborative initiative. Arthritis Rheum 62: 2569-2581, 2010.

23. World Health Organization (WHO): Physical status: The use and interpretation of anthropometry. Report of a WHO Expert Committee. World Health Organ Tech Rep Ser 854: 1-452, 1995.

24. Casciaro S, Conversano F, Pisani P and Muratore M: New perspectives in echographic diagnosis of osteoporosis on hip and spine. Clin Cases Miner Bone Metab 12: 142-150, 2015.

25. Conversano F, Franchini R, Greco A, Soloperto G, Chiriacó F, Casciaro E, Aventaggiato M, Renna MD, Pisani P, Di Paola M, et al: A novel ultrasound methodology for estimating spine mineral density. Ultrasound Med Biol 41: 281-300, 2015. 
26. Olszynski WP, Adachi JD, Hanley DA, Davison KS and Brown JP: Comparison of speed of sound measures assessed by multisite quantitative ultrasound to bone mineral density measures assessed by Dual-energy X-Ray absorptiometry in a large canadian cohort: The canadian multicentre osteoporosis study (CaMos). J Clin Densitom 19: 234-241, 2016.

27. Kanis JA, McCloskey EV, Johansson H, Oden A, Ström O and Borgström F: Development and use of FRAX in osteoporosis. Osteoporos Int 21 (Suppl 2): S407-S413, 2010.

28. Glüer CC, Lu Y and Engelke K: Quality and performance measures in bone densitometry. Part 2: Fracture risk. Osteoporos Int 17: 1449-1458, 2006

29. Hauser B, Riches PL, Wilson JF, Horne AE and Ralston SH: Prevalence and clinical prediction of osteoporosis in a contemporary cohort of patients with rheumatoid arthritis. Rheumatology (Oxford) 53: 1759-1766, 2014.

30. Lee JH, Sung YK, Choi CB, Cho SK, Bang SY, Choe JY, Hong SJ, Jun JB, Kim TH, Lee J, et al: The frequency of and risk factors for osteoporosis in Korean patients with rheumatoid arthritis. BMC Musculoskelet Disord 17: 98, 2016.

31. Mobini M, Kashi Z and Ghobadifar A: Prevalence and associated factors of osteoporosis in female patients with rheumatoid arthritis. Caspian J Intern Med 3: 447-450, 2012.

32. Hwang J, Lee EK, Ahn JK, Cha HS, Koh EM and Lee J: Bone-density testing interval and transition to osteoporosis in patients with rheumatoid arthritis. Osteoporos Int 28: 231-237, 2017.

33. Coulson KA, Reed G, Gilliam BE, Kremer JM and Pepmueller PH: Factors influencing fracture risk, T score, and management of osteoporosis in patients with rheumatoid arthritis in the Consortium of Rheumatology Researchers of North America (CORRONA) registry. J Clin Rheumatol 15: 155-160, 2009.

34. Zhou R, Lin X, Li DY, Wang XF, Greenbaum J, Chen YC, Zeng CP, Lu JM, Ao ZX, Peng LP, et al: Identification of nove genetic loci for osteoporosis and/or rheumatoid arthritis using cFDR approach. PLoS One 12: e0183842, 2017.

35. Gong X, Xu SQ, Wu Y, Ma CC, Qi S, Liu W and Xu JH: Elevated serum $14-3-3 \eta$ protein may be helpful for diagnosis of early rheumatoid arthritis associated with secondary osteoporosis in Chinese population. Clin Rheumatol 36: 2581-2587, 2017.

36. Hussien YM, Shehata A, Karam RA, Alzahrani SS, Magdy H and El-Shafey AM: Polymorphism in vitamin D receptor and osteoprotegerin genes in Egyptian rheumatoid arthritis patients with and without osteoporosis. Mol Biol Rep 40: 3675-3680, 2013.

37. Mosaad YM, Hammad EM, Fawzy Z, Abdal Aal IA, Youssef HM, ElSaid TO, Monir R and El-Deek BS: Vitamin D receptor gene polymorphism as possible risk factor in rheumatoid arthritis and rheumatoid related osteoporosis. Hum Immunol 75: 452-461, 2014.
38. Mohamed RH, Mohamed RH and El-Shahawy EE: Relationship Between RANK and RANKL gene polymorphisms with osteoporosis in rheumatoid arthritis patients. Genet Test Mol Biomarkers 20: 249-254, 2016.

39. Popescu C, Bojincă V, Opriș D and Ionescui R: Dual X-ray absorptiometry whole body composition of adipose tissue in rheumatoid arthritis. Rom J Intern Med 53: 237-247, 2015.

40. Challal S, Minichiello E, Boissier MC and Semerano L: Cachexia and adiposity in rheumatoid arthritis. Relevance for disease management and clinical outcomes. Joint Bone Spine 83: 127-133, 2016.

41. Doğan SC, Hizmetli S, Hayta E, Kaptanoğlu E, Erselcan T and Güler E: Sarcopenia in women with rheumatoid arthritis. Eur J Rheumatol 2: 57-61, 2015.

42. Ngeuleu A, Allali F, Medrare L, Madhi A, Rkain H and Hajjaj-Hassouni N: Sarcopenia in rheumatoid arthritis: Prevalence, influence of disease activity and associated factors. Rheumatol Int 37: 1015-1020, 2017.

43. Mazocco L and Chagas P: Association between body mass index and osteoporosis in women from northwestern Rio Grande do Sul. Rev Bras Reumatol Engl Ed 57: 299-305, 2017 (In English, Portuguese).

44. Cui R, Zhou L, Li Z, Li Q, Qi Z and Zhang J: Assessment risk of osteoporosis in Chinese people: Relationship among body mass index, serum lipid profiles, blood glucose, and bone mineral density. Clin Interv Aging 11: 887-895, 2016.

45. Guimarães M, da Costa Pinto MR, Raid R, Andrade MV and Kakehasi AM: Which is the best cutoff of body mass index to identify obesity in female patients with rheumatoid arthritis? A study using dual energy X-ray absorptiometry body composition. Rev Bras Reumatol: Feb 11, 2016 (Epub ahead of print).

46. Crepaldi G, Romanato G, Tonin P and Maggi S: Osteoporosis and body composition. J Endocrinol Invest 30 (6 Suppl): S42-S47, 2007.

47. Book C, Karlsson MK, Nilsson JA, Akesson K and Jacobsson LT: Changes in body composition after 2 years with rheumatoid arthritis. Scand J Rheumatol 40: 95-100, 2011.

48. Popescu C, Bojinca V, Opris D and Ionescu R: Disease activity predicts whole body and regional lean tissue in rheumatoid arthritis-a cross-sectional study. Romanian J Rheumatol 23: 74-83, 2015.

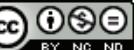

This work is licensed under a Creative Commons Attribution-NonCommercial-NoDerivatives 4.0 International (CC BY-NC-ND 4.0) License. 